ARTICLE

https://doi.org/10.1038/s41467-019-08804-y

\title{
Genesis of electron deficient Pt1(0) in PDMS-PEG aggregates
}

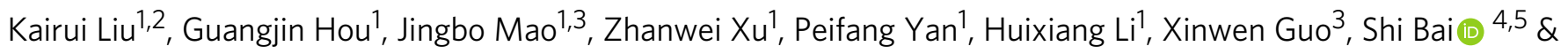
Z. Conrad Zhang (iD) ${ }^{1}$

While numerous single atoms stabilized by support surfaces have been reported, the synthesis of in-situ reduced discrete metal atoms weakly coordinated and stabilized in liquid media is a more challenging goal. We report the genesis of mononuclear electron deficient $\mathrm{Pt}_{1}(0)$ by reducing $\mathrm{H}_{2} \mathrm{PtCl}_{6}$ in liquid polydimethylsiloxane-polyethylene glycol (PDMS-PEG) ( $\left.\mathrm{Pt}_{1} @ P D M S-P E G\right) . U V-V i s$, far-IR, and X-ray photoelectron spectroscopies evidence the reduction of $\mathrm{H}_{2} \mathrm{PtCl}_{6}$. $\mathrm{CO}$ infrared, and ${ }^{195} \mathrm{Pt}$ and ${ }^{13} \mathrm{C} \mathrm{NMR}$ spectroscopies provide strong evidence of $\mathrm{Pt}_{1}(0)$, existing as a pseudo-octahedral structure of $\left(\mathrm{R}^{1} \mathrm{OR}\right)_{2} \mathrm{Pt}(0) \mathrm{Cl}_{2} \mathrm{H}_{2}\left(\mathrm{R}^{1}\right.$ and $\mathrm{R}^{2}$ are $\mathrm{H}, \mathrm{C}$, or Si groups accordingly). The weakly coordinated $\left(\mathrm{R}^{1} \mathrm{OR}{ }^{2}\right)_{2} \mathrm{Pt}(\mathrm{O}) \mathrm{Cl}_{2} \mathrm{H}_{2}$ structure and electron deficient $\mathrm{Pt}_{1}(\mathrm{O})$ have been validated by comparing experimental and DFT calculated ${ }^{195} \mathrm{Pt}$ NMR spectra. The $\mathrm{H}^{+}$in protic state and the $\mathrm{Cl}^{-}$together resemble $\mathrm{HCl}$ as the weak coordination. Neutralization by a base causes the formation of Pt nanoparticles. The $\mathrm{Pt}_{1} @ P D M S-P E G$ shows ultrahigh activity in olefin hydrosilylation with excellent terminal adducts selectivity.

\footnotetext{
${ }^{1}$ State Key Laboratory of Catalysis, Dalian National Laboratory for Clean Energy, Dalian Institute of Chemical Physics, Chinese Academy of Sciences, 457 Zhongshan Road, 116023 Dalian, Liaoning, China. ${ }^{2}$ University of Chinese Academy of Sciences, 100049 Beijing, China. ${ }^{3}$ State Key Laboratory of Fine Chemicals, PSU-DUT Joint Centre for Energy Research, School of Chemical Engineering, Dalian University of Technology, 116024 Dalian, China. ${ }^{4}$ Department of Chemistry and Biochemistry, University of Delaware, Newark, DE 19716, USA. ${ }^{5}$ State Key Laboratory of Applied Organic Chemistry, Lanzhou University, 730000 Lanzhou, Gansu, China. Correspondence and requests for materials should be addressed to Z.C.Z. (email: zczhang@dicp.ac.cn) or to S.B. (email: bais@udel.edu)
} 
S upported single atoms have been prepared using various methods ${ }^{1,2}$. The reduced metal atoms are stabilized on solid surfaces through metal-support interaction ${ }^{3,4}$ or by strong ligand coordination ${ }^{5,6}$. The noble metal atoms are often capable of activating adsorbed reactants in catalysis ${ }^{7,8}$. Reduced single atoms tend to aggregate into nanoparticles in liquid media in the absence of strong ligand coordination ${ }^{9}$. Full and strong coordination is not desired for metal catalysts ${ }^{10}$. Therefore, synthesis of weakly coordinated and yet stable metal atoms in liquid media may pave a new path for facile preparation of highly dispersed metal catalysts by overcoming the long-standing challenge of metal aggregation. The readily removable ligands from the discrete metal atoms may also potentially enable atomically controllable synthesis of metallic materials by design.

Numerous surfactants with diverse functionalities have been used in the synthesis of metallic nanoparticles ${ }^{11,12}$ or metal ionsurfactant complexes ${ }^{13,14}$ in micro-emulsions system. The synthesis of discrete reduced metal atoms with weak coordination, which are sufficiently stable in storage at moderate temperature has not been reported. In this work, we chose polydimethylsiloxane-polyethylene glycol (PDMS-PEG) copolymer as an amphiphilic solvating agent. The hydrophilic and semicrystalline PEG blocks enable the dispersion of the hydrophobic PDMS blocks in aqueous solutions ${ }^{15,16}$. In our synthesis, ethanol is used as the reductant for $\mathrm{Pt}(\mathrm{IV})^{17,18}$, in the presence of optimized $10 \%(\mathrm{v} / \mathrm{v})$ water to accelerate the rate of reduction ${ }^{9}$, while the diverse oxygen-containing functionality of PDMS-PEG offer weak coordination to the $\mathrm{Pt}$ atoms.

\section{Results \& discussion}

Formation and spectroscopic characterizations of $\mathrm{Pt}_{1}(0)$ in ethanol reduction of ionic $\mathrm{Pt}$ precursors. Weakly coordinated mononuclear $\mathrm{Pt}_{1}(0)\left(\mathrm{Pt}_{1} @ \mathrm{PDMS}-\mathrm{PEG}\right)$ was prepared by ethanol reduction of $\mathrm{H}_{2} \mathrm{PtCl}_{6}$ in PDMS-PEG/ethanol-water (see Methods). The characteristic ultraviolet (UV)-visible (Vis) absorption peak of $\left[\mathrm{PtCl}_{6}\right]^{2-}$ at $265 \mathrm{~nm}$ disappeared and that of $\left[\mathrm{PtCl}_{4}\right]^{2-}$ anions at $220 \mathrm{~nm}$ was absent ${ }^{17,18}$ after the solution was refluxed for $3 \mathrm{~h}$ at $105^{\circ} \mathrm{C}$, indicating complete reduction of the Pt ions (Fig. 1a). While the decrease of the signal at $329 \mathrm{~cm}^{-1}$ in far infrared spectra ${ }^{19,20}$ (Fig. 1b) confirmed the loss of Coulombic Pt-Cl bonds, characterized by the chlorides of positively charged $\mathrm{Pt}$ ions, the retained $\mathrm{Cl}$ with a $\mathrm{Cl} / \mathrm{Pt}$ atomic ratio of 2 in $\mathrm{Pt}_{1} @ P D M S-P E G$ was determined by chloride ion-chromatography analysis (Supplementary Table 1). Concomitant with the reduction of Pt(IV) (Supplementary Table 2), the color of the solution turned from bright yellow to colorless. Furthermore, the characteristic broad peak of Pt nanoparticles between 400 and $800 \mathrm{~nm}$ was not observed (Fig. 1a), indicating the absence of $\mathrm{Pt}_{\mathrm{n}}$ clusters in the system ${ }^{21}$. When PDMSPEG was replaced by either PDMS or PEG alone, a dark brown color indicative of $\mathrm{Pt}$ nanoparticle formation was observed under the same conditions ${ }^{18}$.

The absence of ${ }^{195} \mathrm{Pt}$ nuclear magnetic resonance (NMR) signals near $0 \mathrm{ppm}^{22,23}$ for $\left[\mathrm{PtCl}_{6}\right]^{2-}$ and $-1617 \mathrm{ppm}^{24}$ for $\left[\mathrm{PtCl}_{4}\right]^{2-}$ confirms the full reduction of platinum. Meanwhile, a pronounced ${ }^{195} \mathrm{Pt}$ NMR peak at $-2680 \mathrm{ppm}$ (Fig. 2a1) was observed and assigned to $\mathrm{Pt}_{1}(0)$ in PDMS-PEG. This conclusion has been independently verified by the reduction of $\left[\mathrm{PtCl}_{4}\right]^{2-}$ in PDMS-PEG monitored by ${ }^{195} \mathrm{Pt}$ NMR (Supplementary Fig. 1). ${ }^{195} \mathrm{Pt}$ NMR calculation of $\mathrm{Pt}(\mathrm{II})$ in $\mathrm{PtCl}_{2} \mathrm{~L}_{2}$ or binuclear $\mathrm{Pt}_{2}(\mu$ $\mathrm{Cl})_{2} \mathrm{Cl}_{2} \mathrm{~L}_{2}$ complexes with bridging $\mathrm{Cl}$ ligands (Supplementary Table 3) also supports the reduced state of $\mathrm{Pt}_{1}$ center ${ }^{25}$.

$\mathrm{CO}$ has been widely used to probe the dispersion of $\mathrm{Pt}$ particles on supports ${ }^{4}$. $\mathrm{CO}$ is known to coordinate to $\mathrm{Pt}$ by forming a linear $\mathrm{Pt}-\mathrm{CO}$ bond or bridged bonds $\left(\mathrm{Pt}_{2} \mathrm{CO}\right.$ and $\left.\mathrm{Pt}_{3} \mathrm{CO}\right)$ on the surface of Pt clusters ${ }^{4}$. The identity of the discrete mononuclear state of $\mathrm{Pt}$ atoms was further verified by $\mathrm{CO}$ coordination using ${ }^{195} \mathrm{Pt}$ and ${ }^{13} \mathrm{C}$ NMR spectroscopy. ${ }^{13} \mathrm{CO}$ treatment of $\mathrm{Pt}_{1} @ P D M S-P E G$ (Methods) led to an up-field shift of the ${ }^{195} \mathrm{Pt}$ peak from -2680 to $-3231 \mathrm{ppm}$ as a doublet with a splitting of $1750 \mathrm{~Hz}$, (Fig. 2b1), corresponding to one CO coordination to one $\mathrm{Pt}_{1}(0)$ center. The ${ }^{13} \mathrm{C}$ NMR spectrum (Fig. 2b2) of this sample also showed a new peak at $150.4 \mathrm{ppm}$ with a ${ }^{195} \mathrm{Pt}$ satellite doublet $\left({ }^{195} \mathrm{Pt}-{ }^{13} \mathrm{CO}\right)$ having the same splitting $(1750 \mathrm{~Hz})$. Since the ${ }^{13} \mathrm{C}$ NMR chemical shift of solvated $\mathrm{CO}$ in various solvents ranges from 184.9 to $188.0 \mathrm{ppm}^{26}$, the peak at $150.4 \mathrm{ppm}$ can be assigned to the carbon of the newly formed Pt $\bullet \bullet C=O$ species. In concert with the experimental observation, the density functional theory (DFT) calculation of ${ }^{13} \mathrm{C}$ NMR chemical shift also shows a $24.1 \mathrm{ppm}$ up-field shift from the gas phase $\mathrm{CO}$ to Pt.••C $=\mathrm{O}$ (Entries 8, 13 in Supplementary Table 4).

In both ${ }^{195} \mathrm{Pt}$ and ${ }^{13} \mathrm{C}$ NMR spectra, the splitting of $1750 \mathrm{~Hz}$ can be unambiguously assigned as the spin-spin coupling constant ${ }^{1} \boldsymbol{J}\left({ }^{195} \mathrm{Pt}-{ }^{13} \mathrm{C}\right)$. ${ }^{13} \mathrm{CO}$ coordination to any form of multi-nuclear platinum cluster would produce more complex spin-spin coupling patterns than a simple doublet (Fig. 2b) of a linear Pt..॰C $=\mathrm{O}$ structure. Thus, we conclude that the observed ${ }^{195} \mathrm{Pt}$ NMR data unambiguously demonstrate the discrete mononuclear state of $\mathrm{Pt}$ atoms and $\mathrm{Pt}_{1} \bullet \bullet \mathrm{C}=\mathrm{O}$ species, respectively.

When a concentrated $\mathrm{Pt}_{1} @ P D M S-P E G$ solution was purged with $\mathrm{CO}$ (Methods), a new peak at $341 \mathrm{~cm}^{-1}$ (vibration of $\mathrm{Pt}_{1}-\mathrm{CO}$ ) in far infrared appeared ${ }^{19,20}$ (Supplementary Fig. 2). Altogether with the ${ }^{195} \mathrm{Pt}$ NMR signal shift to $-3231 \mathrm{ppm}$ after the ${ }^{13} \mathrm{CO}$ treatment, the results indicate that $\mathrm{CO}$ is a strong ligand. The
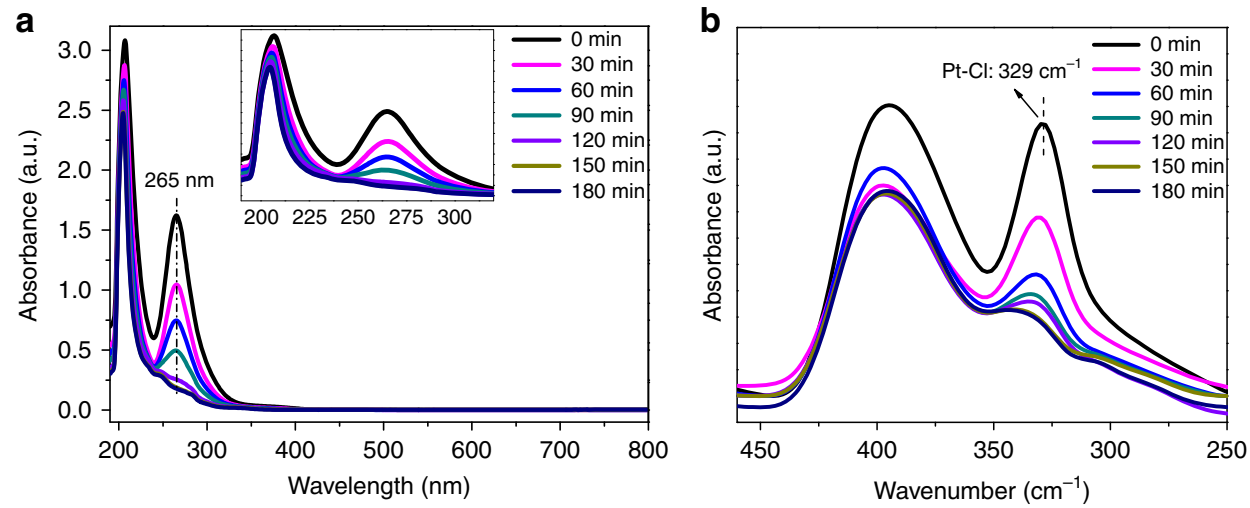

Fig. 1 The reduction of $\mathrm{H}_{2} \mathrm{PtCl}_{6}$. a Ultraviolet (UV)-visible (Vis) spectra of $\mathrm{H}_{2} \mathrm{PtCl}_{6}$ during the ethanol reduction process. b Far infrared spectra in the process of $\mathrm{H}_{2} \mathrm{PtCl}_{6}$ reduction 


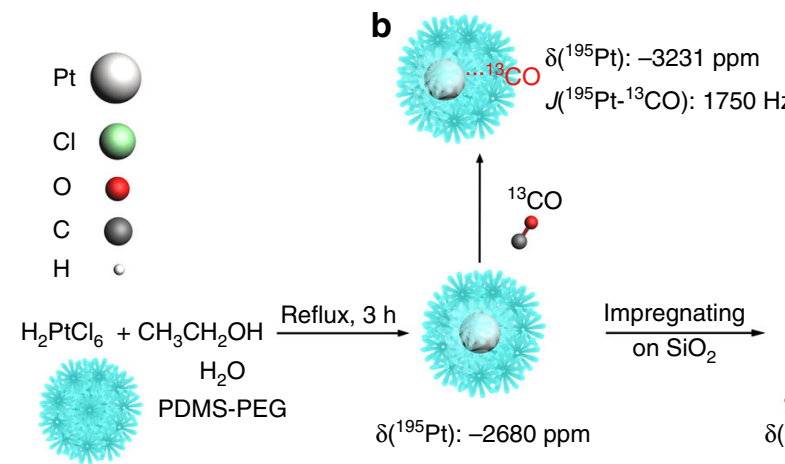

a

$\left.\left(\mathrm{R}^{1} \mathrm{OR}\right)_{2}\right)_{2} \mathrm{Pt}(0) \mathrm{Cl}_{2}^{-} \mathrm{H}^{+}{ }_{2}$ f



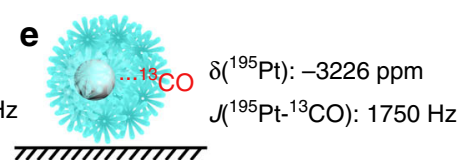

77777717777

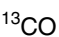

${ }^{13} \mathrm{CO}$



गा

$\delta\left({ }^{195} \mathrm{Pt}\right):-2674 \mathrm{ppm} \quad \delta\left({ }^{195} \mathrm{Pt}\right):-3226 \mathrm{ppm}$

C

d

Fig. $2{ }^{195} \mathrm{Pt}$ NMR (a1-e1) and corresponding ${ }^{13} \mathrm{C}$ NMR (a2-e2) spectra of a Pt $@$ PDMS-PEG liquid; b ${ }^{13} \mathrm{CO}$ treated Pt $@$ PDMS-PEG liquid; c 2 wt\% $\mathrm{Pt}_{1} @ \mathrm{PDMS}-\mathrm{PEG} / \mathrm{SiO}_{2} ; \mathbf{d} \mathrm{CO}$ treated 2 wt\% Pt $@$ PDMS-PEG $/ \mathrm{SiO}_{2} ; \mathbf{e}^{13} \mathrm{CO}$ treated 2 wt\% $\mathrm{Pt}_{1} @ \mathrm{PDMS}-\mathrm{PEG} / \mathrm{SiO}{ }_{2}$. Note: 2 wt\% refers to the Pt loading on $\mathrm{SiO}_{2} ; \mathbf{f}, \mathbf{g}$ are the selected density functional theory (DFT) models of pseudo octahedral structure of $\left(\mathrm{R}^{1} \mathrm{OR}^{2}\right)_{2} \mathrm{Pt}(0) \mathrm{Cl}^{-}{ }_{2} \mathrm{H}^{+}{ }_{2}\left(\mathrm{R}^{1}, \mathrm{R}^{2}\right.$ are $\mathrm{H}_{1} \mathrm{C}$, or $\mathrm{Si}$ groups) and $\left(\mathrm{R}^{1} \mathrm{OR}^{2}\right) \mathrm{Pt}(\mathrm{O}) \mathrm{Cl}^{-}{ }_{2} \mathrm{H}^{+}{ }_{2} \mathrm{CO}$ in polydimethylsiloxane-polyethylene glycol (PDMS-PEG), respectively. Note: the sketch only serves as an illustration of possible local structures

${ }^{195} \mathrm{Pt}$ NMR linewidth of $265 \mathrm{~Hz}$ for $\mathrm{Pt}_{1} \bullet \bullet \mathrm{C}=\mathrm{O}$, almost fivefold reduction from that of solvated $\mathrm{Pt}_{1} @ \mathrm{PDMS}-\mathrm{PEG}$, may be attributed to the enhanced mobility in the vicinity of $\mathrm{Pt}$ sites upon formation of the Pt•••C = O bond.

Determination of coordination structure and electronic state of $\mathbf{P t}_{\mathbf{1}}(\mathbf{0})$. Extensive DFT-based structure screening using geometry optimization was followed by validation through comparing the calculated ${ }^{195} \mathrm{Pt}$ chemical shifts of the selected structural models ${ }^{27-29}$ with the experimental shifts. Consistent with the fact that there are two chlorines per $\operatorname{Pt}_{1}(0)$ in $\mathrm{Pt}_{1} @ P D M S-P E G$ based on the chloride ion chromatographic analysis, the DFT survey reveals a set of pseudo octahedral structures $\left(\mathrm{R}^{1} \mathrm{OR}^{2}\right)_{2} \mathrm{Pt}(0) \mathrm{Cl}^{-}{ }_{2} \mathrm{H}^{+}{ }_{2}\left(\mathrm{R}^{1}, \mathrm{R}^{2}\right.$ are $\mathrm{H}, \mathrm{C}$, or $\mathrm{Si}$ groups) (Entries 2-5, Supplementary Table 4) that not only stabilize $\mathrm{Pt}_{1}(0)$, but also leads to the calculated ${ }^{195} \mathrm{Pt}$ chemical shifts in reasonable agreement with the experimental value $(-2680 \mathrm{ppm})$ for $\mathrm{Pt}_{1} @ P D M S-P E G$.

In general, these structures contain two electron-donating oxygens (hydroxyl oxygens of water, ethanol as well as ester oxygens of siloxane and PEG segments) and an otherwise cisdivacant octahedral structure $\left(\mathrm{Pt}_{1} \mathrm{H}_{2} \mathrm{Cl}_{2}\right)$ (Entry 1 , Supplementary Table 4). The DFT calculation indicates the coordination of $\mathrm{Pt}_{1}(0)$ by $\mathrm{H}, \mathrm{Cl}$, and $\mathrm{O}$ simultaneously prevents $\mathrm{Pt}_{1}(0)$ from forming aggregates. We noted that various oxygen coordinated structures, excluding $\mathrm{Cl}$ and $\mathrm{H}$ and the structures in which $\mathrm{H}^{+}$bound to $\mathrm{Cl}^{-}$ failed to produce a structure matching the observed ${ }^{195} \mathrm{Pt}$ 

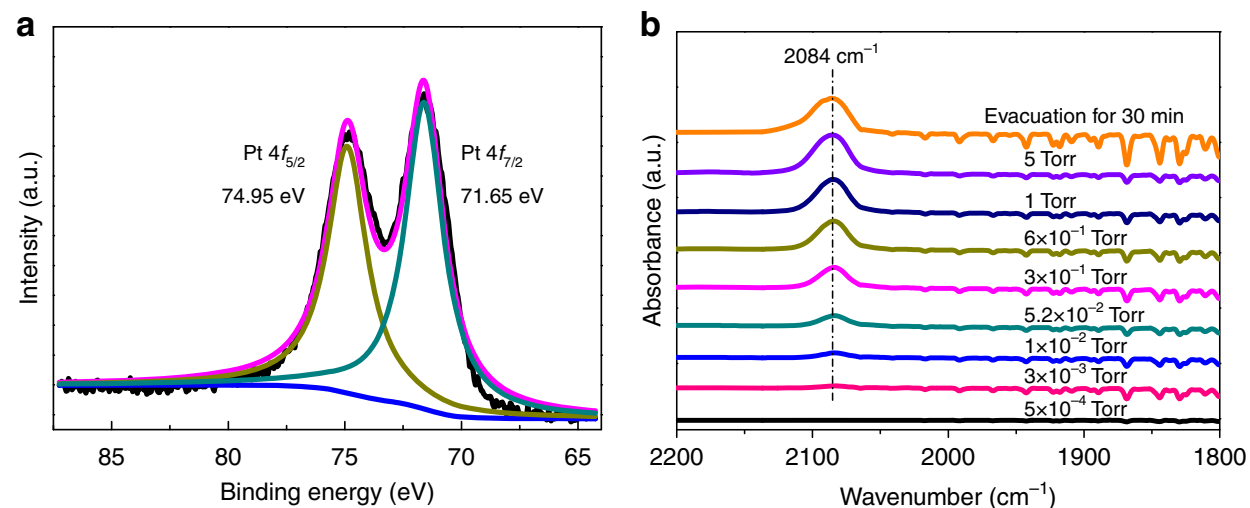

Fig. 3 X-ray photoelectron spectra and $\mathrm{CO}$ adsorption of $\mathrm{Pt}_{1}(0)$ atoms. a X-ray photoelectron spectra of 0.5 wt $\% \mathrm{Pt}_{1} @ \mathrm{PDMS}-\mathrm{PEG} / \mathrm{SiO}_{2}$, and $\mathbf{b}$ In situ diffuse reflectance infrared Fourier-transform (DRIFT) spectroscopy of CO adsorption on 1 wt\% Pt $@ P D M S-P E G / S i O_{2}$

chemical shift (Supplementary Table 4). Moreover, the DFT calculation shows that the Bader charge of $\mathrm{Pt}$ atoms in the optimized structures (Entries 1-5, Supplementary Table 4) is around $0.6 \mathrm{eV}$, indicating the $\operatorname{Pt}_{1}(0)$ atoms are electron deficient $\left(\mathrm{Pt}_{1}{ }^{\delta+}(0<\delta<1)\right)$, possibly associated with the partial electronegative charge of $\mathrm{Cl}^{-}$. The Bader charge of hydrogen is positive for all optimized $\left(\mathrm{R}^{1} \mathrm{OR}^{2}\right)_{2} \mathrm{PtCl}_{2} \mathrm{H}_{2}$ structures (Entries 2-5, Supplementary Table 4), suggesting the $\mathrm{H}$ in $\left(\mathrm{R}^{1} \mathrm{OR}^{2}\right)_{2} \mathrm{PtCl}_{2} \mathrm{H}_{2}$ is similar to labile proton rather than to hydride in nature. In the presence of abundant protons such as in residual $\mathrm{H}_{2} \mathrm{O}$ and $\mathrm{OH}$ groups of the solvent, the protic $\mathrm{H}$ in the $\left(\mathrm{R}^{1} \mathrm{OR}^{2}\right)_{2} \mathrm{PtCl}_{2} \mathrm{H}_{2}$ could be readily hydrated, e.g. $\mathrm{H}_{3} \mathrm{O}^{+}$. The calculated ${ }^{195} \mathrm{Pt}$ chemical shift $(-2705 \mathrm{ppm})$ of $\left(\mathrm{R}^{1} \mathrm{OR}^{2}\right)_{2} \mathrm{Pt}(0) \mathrm{Cl}^{-}{ }_{2}\left(\mathrm{H}_{3} \mathrm{O}^{+}\right)_{2}$ (Entry 6, Supplementary Table 4$)$ is in an excellent agreement with the experimental shift $(-2680 \mathrm{ppm})$, suggesting that $\left(\mathrm{R}^{1} \mathrm{OR}^{2}\right)_{2} \mathrm{Pt}(0)$ $\mathrm{Cl}^{-}{ }_{2}\left(\mathrm{H}_{3} \mathrm{O}^{+}\right)_{2}$ may exist as a hydrated form of $\left(\mathrm{R}^{1} \mathrm{OR}^{2}\right)_{2} \mathrm{PtCl}^{-}{ }_{2} \mathrm{H}$ $+_{2}$ in the system. This calculated result is a further validation of the existence of protic $\mathrm{H}$, rather than a hydride. The absence of ${ }^{195} \mathrm{Pt}^{-1} \mathrm{H}$ spin-spin couplings in the ${ }^{195} \mathrm{Pt}$ spectra may be explained by the rapid chemical exchanges between the protic $\mathrm{H}$ in $\left(\mathrm{R}^{1} \mathrm{OR}^{2}\right)_{2} \mathrm{PtCl}_{2}^{-} \mathrm{H}^{+}{ }_{2}$ and abundant labile protons of water and hydroxyl protons in the system. Furthermore, the protic $\mathrm{H}$ in the $\left(\mathrm{R}^{1} \mathrm{OR}^{2}\right)_{2} \mathrm{Pt}(0) \mathrm{Cl}_{2} \mathrm{H}_{2}$ is consistent with a recent report that showed $\mathrm{HCl}$ acted as a weak ligand in the stabilization of Ir nanoparticles with the $\mathrm{H}$ in protic state ${ }^{30}$. The $\mathrm{PtCl}_{2}{ }^{2-}$ species quickly aggregated to form $\mathrm{Pt}$ nanoparticles in methanol-water solution ${ }^{9}$. In our system, the $\left(\mathrm{R}^{1} \mathrm{OR}^{2}\right)_{2} \mathrm{Pt}(0) \mathrm{Cl}^{-}{ }_{2} \mathrm{H}^{+}{ }_{2}$ is well stabilized by the PDMS-PEG matrix.

Besides the weak coordination of the dioxygen in the liquid, the $\left(\mathrm{R}^{1} \mathrm{OR}^{2}\right)_{2} \mathrm{Pt}(0) \mathrm{Cl}_{2} \mathrm{H}_{2}$ is acidic because of the protic $\mathrm{H}$. We found that the $\mathrm{Cl}$ and $\mathrm{H}$ in $\mathrm{PtCl}_{2} \mathrm{H}_{2}$ are readily removable by neutralization with a base, accompanying with the release and subsequent destabilization of bare $\mathrm{Pt}_{1}{ }^{\delta+}$ atoms even at ambient temperature. The sintering of $\mathrm{Pt}$ under such condition was evidenced by noting the color of the solution changing from colorless to dark brown, which apparently is not associated with $\mathrm{Pt}(\mathrm{II}$ or IV) chlorides. The fact that no redox reaction occurred during the neutralization process confirmed the $\mathrm{Pt}_{1}$ in $\left(\mathrm{R}^{1} \mathrm{OR}^{2}\right)_{2} \mathrm{PtCl}_{2} \mathrm{H}_{2}$ was in reduced state. The Pt coordination with $\mathrm{H}$ and $\mathrm{Cl}$ further verified by $\mathrm{HBr}$ exchange, which led an up-field ${ }^{195} \mathrm{Pt}$ NMR chemical shift of $\left(\mathrm{R}^{1} \mathrm{OR}^{2}\right)_{2} \mathrm{PtBr}^{-}{ }_{2} \mathrm{H}^{+}{ }_{2}$ to $-3399 \mathrm{ppm}$ (Supplementary Fig. 3), as was predicted by the calculated ${ }^{195} \mathrm{Pt}$ NMR value ( $-3197 \mathrm{ppm}$, Entry 7, Supplementary Table 4).

To further verify the pseudo octahedral structures with a $\mathrm{CO}$ coordination as Pt... C = O, we replaced one of oxygencontaining groups $\left(\mathrm{R}^{1} \mathrm{OR}^{2}\right)$ with $\mathrm{CO}$, followed by DFT geometry optimization and ${ }^{195} \mathrm{Pt}$ NMR chemical shift calculation. The corresponding optimized structures (Entries 9-12, Supplementary Table 4) yielded the calculated ${ }^{195} \mathrm{Pt}$ chemical shifts again in acceptable agreement with the experimental value $(-3231 \mathrm{ppm})$ of Pt $\ldots \mathrm{C}=\mathrm{O}$. A model without proper oxygen coordination (Entry 8, Supplementary Table 4) failed to produce ${ }^{195} \mathrm{Pt}$ chemical shift in conformity to the experimental value. Experimentally, the ${ }^{195} \mathrm{Pt}$ chemical shift is up-field shifted by 551 ppm from $\mathrm{Pt}_{1} @ P D M S-P E G$ to the CO treated $\mathrm{Pt}_{1} @ P D M S-$ PEG. ${ }^{195} \mathrm{Pt}$ chemical shift calculation shows that one CO coordination replacing one of the two $\mathrm{R}^{1} \mathrm{OR}^{2}$ coordination (Entries 9-12, Supplementary Table 4) led to an up-field shift ranging from 366 to $489 \mathrm{ppm}$ compared to the corresponding dioxygen coordinated structures (Entries 2-5, Supplementary Table 4), in remarkable agreement with the experimental up-field shift value of $551 \mathrm{ppm}$. At the same time, replacing the first $\mathrm{R}^{1} \mathrm{OR}^{2}$ group with CO is energetically favored $(\Delta E=-0.18 \mathrm{eV})$. Further replacement of the remaining $\mathrm{R}^{1} \mathrm{OR}^{2}$ with a $\mathrm{CO}$ resulted in negligible energy difference $(\Delta E=-0.04 \mathrm{eV})$, consistent with fact that only one CO binds to $\mathrm{Pt}_{1}{ }^{\delta+}$ atom. DFT calculation also shows that di-coordinated $\mathrm{Pt}(\mathrm{II})$ structures, trans- $\mathrm{Pt}(\mathrm{II}) \mathrm{Cl}_{2}(\mathrm{CO})_{2}$ and cis- $\mathrm{Pt}(\mathrm{II}) \mathrm{Cl}_{2}(\mathrm{CO})_{2}$, could not produce predicted chemical shifts in agreement with the experimentally observed value $-3231 \mathrm{ppm}$ (Supplementary Table 5). In addition, unlike $\left(\mathrm{R}^{1} \mathrm{OR}^{2}\right) \mathrm{Pt}(0) \mathrm{Cl}_{2} \mathrm{H}_{2}$, the formation of dicarbonyl complex, $\mathrm{Pt}(\mathrm{II})$ $\mathrm{Cl}_{2}(\mathrm{CO})_{2}$, from $\mathrm{Pt}(\mathrm{II}) \mathrm{Cl}_{2}\left(\mathrm{R}^{1} \mathrm{OR}^{2}\right)$ is energetically favorable by the DFT calculations (Supplementary Table 5).

To demonstrate the versatility of preparing supported mononuclear electron-deficient $\mathrm{Pt}$ from the liquid $\mathrm{Pt}_{1}(0)$ precursor, a $\mathrm{Pt}_{1} @ \mathrm{PDMS}-\mathrm{PEG} / \mathrm{SiO}_{2}$ sample with Pt loading equivalent to 2.0 wt\% with respect to $\mathrm{SiO}_{2}$ was prepared (see Methods). In comparison, a low Pt loading, e.g., $0.17 \mathrm{wt} \%$, was essential for the direct preparation of $\mathrm{Pt}$ single atoms on oxides support ${ }^{4}$ to minimize $\mathrm{Pt}$ sintering due to its weak interaction with the support. Solid-state ${ }^{195} \mathrm{Pt}$ magic angle spinning (MAS) NMR spectrum (Figure 2c1) of the $\mathrm{Pt}_{1} @ \mathrm{PDMS}-\mathrm{PEG} / \mathrm{SiO}_{2}$ showed a peak at -2674 ppm, resembling that of $\mathrm{Pt}_{1} @ \mathrm{PDMS}-\mathrm{PEG}$ in terms of chemical shift. After CO treatment (see Methods), the ${ }^{195} \mathrm{Pt}$ peak was shifted up-field to $-3226 \mathrm{ppm}$ (Figure 2d1). The same ${ }^{1} J\left({ }^{195} \mathrm{Pt}-{ }^{13} \mathrm{C}\right)$ values were simultaneously observed in the ${ }^{195} \mathrm{Pt}$ and ${ }^{13} \mathrm{C}$ MAS NMR spectra (Figs. 2e1 and e2) upon ${ }^{13} \mathrm{CO}$ treatment of the $\mathrm{Pt}_{1} @ \mathrm{PDMS}-\mathrm{PEG} / \mathrm{SiO}_{2}$ sample, indicating that $\mathrm{Pt}_{1} @ P D M S-P E G$ was well preserved and stably dispersed on the silica surface even after "drying" under vacuum at $40^{\circ} \mathrm{C}$. Remarkably, the $\mathrm{Pt}_{1} @ P D M S-P E G$ and $\mathrm{Pt}_{1} @ P D M S-P E G / \mathrm{SiO}_{2}$ samples remained stable for over six months in storage at ambient temperature as evidenced by almost identical ${ }^{195} \mathrm{Pt}$ NMR spectra periodically measured. 
To further verify the oxidation state of Pt after the reduction, a $\mathrm{Pt}_{1} @$ PDMS-PEG liquid sample impregnated on pristine $\mathrm{SiO}_{2}$ was studied by X-ray photoelectron spectroscopy (XPS) (Fig. 3a). A peak at $71.65 \mathrm{eV}\left(\mathrm{Pt} 4 f_{7 / 2}\right)$, which is $0.45 \mathrm{eV}$ higher than that of bulk Pt metal $(71.20 \mathrm{eV})^{31}$ and $1.55 \mathrm{eV}$ lower than that of Pt(II) $(73.20 \mathrm{eV})^{32}$, confirmed the reduced state of $\mathrm{Pt}$ atoms in $\mathrm{Pt}_{1} @ \mathrm{PDMS}-\mathrm{PEG} / \mathrm{SiO}_{2}$. Only one infrared (IR) absorption peak at $2084 \mathrm{~cm}^{-1}$ was observed for CO adsorbed on $\mathrm{Pt}_{1} @$ PDMSPEG/SiO 2 , but not on PDMS-PEG/SiO 2 (Supplementary Fig. 4) by in situ diffuse reflectance infrared Fourier-transform (DRIFT) spectroscopy (Fig. 3b). Peak between 1800 and $1900 \mathrm{~cm}^{-1}$ for bridged CO was not observed, and the peak at $2084 \mathrm{~cm}^{-1}$ did not shift with increasing $\mathrm{CO}$ pressure, indicating the absence of nanoparticles in the system ${ }^{4}$. The DRIFT result is consistent with the NMR results of CO treated $\mathrm{Pt}_{1} @ P D M S-P E G$ (one-to-one coordination between $\mathrm{CO}$ and $\mathrm{Pt}_{1}{ }^{\delta+}$ center), and the characteristic peaks at 2178 and $2138 \mathrm{~cm}^{-1}$ corresponding to the cis-Pt(II) $\mathrm{Cl}_{2}(\mathrm{CO})_{2}$ were absent ${ }^{33}$.

The morphology of $\mathrm{Pt}_{1} @ P D M S-P E G$ solution was characterized by transmission electron microscopy (TEM). Fairly unilamellar vesicles with a narrow distribution $(30-80 \mathrm{~nm}$, Supplementary Fig. 5a) were formed ${ }^{34}$. The energy-dispersive $\mathrm{X}$-ray spectroscopy analysis in a scanning transmission electron microscope (STEM) revealed the existence of $\mathrm{Pt}$ in the vesicles (Supplementary Fig. 5b and Supplementary Table 6). It should be noted that the Pt atoms tend to agglomerate under intense electron beam or X-ray radiation, making TEM, STEM, and synchrotron X-ray measurements infeasible in providing unambiguous evidence of discrete $\mathrm{Pt}$ atoms in our system ${ }^{35}$.

Catalytic performance of electron deficient $\mathrm{Pt}_{1}(0)$ in hydrosilylation reactions. An application of $\mathrm{Pt}_{1} @ \mathrm{PDMS}-\mathrm{PEG}$ as demonstrated in this work is its superb performance in hydrosilylation reaction 36,37 . $\mathrm{Pt}_{1} @$ PDMS-PEG exhibited an ultrahigh activity with high selectivity (99\%) to the terminal adduct in the benchmark hydrosilylation reaction of 1-octene and $\left(\mathrm{Me}_{3} \mathrm{SiO}\right)_{2^{-}}$ $\mathrm{MeSiH}$ (Supplementary Table 7 and Supplementary Fig. 6). No 1octene conversion was observed in a blank test using PDMS-PEG alone (Supplementary Table 7). The turnover frequency (TOF) of the $\mathrm{Pt}_{1} @ P D M S-P E G$ catalyst is 2 to 4 orders of magnitude higher than that of Karstedt ${ }^{38}$, NHC-Pt complexs ${ }^{37,39}$, and silylene-Pt complexs ${ }^{38,40}$ (Supplementary Table 7 and Supplementary Fig. 7). The turnover number (TON) exceeded $5.0 \times 10^{8}$ for the hydrosilytion reaction of 1-octene using $\left(\mathrm{Me}_{3} \mathrm{SiO}\right)_{2} \mathrm{MeSiH}$ as the silylation reagent. Induction period of the hydrosilylation by $\mathrm{Pt}_{1} @ \mathrm{PDMS}-\mathrm{PEG}$ was negligible. The reaction solution remained colorless and transparent throughout hydrosilylation reaction.

The ultrahigh activity of $\mathrm{Pt}_{1} @$ PDMS-PEG catalyst may be attributed to electron deficiency of the $\mathrm{Pt}_{1}{ }^{\delta+}$ center ${ }^{41}$ and the reversible weakly electron-donating $\mathrm{R}^{1} \mathrm{OR}^{2}$ ligands as compared to the 1,3-divinyl-1,1,3,3-tetramethyldisiloxane (dvtms) or other olefin ligands. The Bader charge $(\sim 0.6 \mathrm{eV})$ on the $\mathrm{Pt}_{1}{ }^{\delta+}$ center in $\left(\mathrm{R}^{1} \mathrm{OR}^{2}\right)_{2} \mathrm{PtCl}_{2} \mathrm{H}_{2}$ (Entries 2-5, Supplementary Table 4) is much higher than the charge $(0.13 \mathrm{eV})$ for $\mathrm{Pt}$ in the tri-olefin coordinated complex (Entry 9, Supplementary Table 8), representing Karstedt $\mathrm{Pt}$ catalyst. ${ }^{195} \mathrm{Pt}$ chemical shift of the $\mathrm{Pt}_{1} @$ PDMS-PEG is about $3450 \mathrm{ppm}$ down-field shifted to that of the Karstedt Pt catalyst ${ }^{42}$, also in conformity with the high electron deficiency of the $\mathrm{Pt}_{1} @ \mathrm{PDMS}-\mathrm{PEG}$ catalyst. The dvtms coordinated Pt catalysts are typically characterized by a relative long induction period partly due to the slow substitution of dvtms by reactants ${ }^{39}$.

When 1-octene was added to $\mathrm{Pt}_{1} @ \mathrm{PDMS}-\mathrm{PEG}$, the ${ }^{195} \mathrm{Pt} \mathrm{NMR}$ peak showed an insignificant up-field shifted by only $26 \mathrm{ppm}$ to -2706 ppm (Supplementary Fig. 8). DFT calculation shows that only mono-olefin complex (olefin) ${ }_{1}\left(\mathrm{R}^{1} \mathrm{OR}^{2}\right)_{1} \mathrm{PtCl}^{-}{ }_{2} \mathrm{H}^{+}$produces a ${ }^{195} \mathrm{Pt}$ NMR chemical shift that reasonably agrees with the experimentally observed value (Entry 2, Supplementary Table 8 ). All structures with multiple olefin coordination fail to predict the experimental ${ }^{195} \mathrm{Pt}$ NMR chemical shift. The dvtms stabilized Pt catalysts were reported to form colloidal platinum species, accompanied by the change of the solution color to yellow during the hydrosilylation catalysis process ${ }^{43,44}$, making the nuclearity of the active Pt catalyst debatable. In this work, in addition to the invariant color throughout the hydrosilylation reaction, the ${ }^{195} \mathrm{Pt}$ NMR of the reaction solution after the catalytic reaction shows that the catalyst remained in mononuclear $\mathrm{Pt}_{1}(0)$ state (Supplementary Fig. 9, $n_{1 \text {-octene }}: n_{\text {silane }}=5: 3$ ), suggesting that the highly durable mononuclear $\operatorname{Pt}_{1}(0)$ center is the active site in $\mathrm{Pt}_{1} @ P D M S-P E G$ for the reaction. Moreover, through three recycled uses, $\mathrm{Pt}_{1} @ P D M S-P E G$ maintained high activity without noticeable deactivation in 1-octene hydrosilylation with $\left(\mathrm{Me}_{3} \mathrm{SiO}\right)_{2} \mathrm{MeSiH}$ (Supplementary Fig. 10). The color of the reused $\mathrm{Pt}_{1} @ \mathrm{PDMS}$-PEG solution remained clear throughout the reuses.

Conclusion. We prepare discrete $\mathrm{Pt}_{1} @ \mathrm{PDMS}$-PEG through ethanol reduction of $\mathrm{H}_{2} \mathrm{PtCl}_{6}$. UV-Vis, Fourier-transform infrared spectroscopy (FTIR), ${ }^{195} \mathrm{Pt}$, and ${ }^{13} \mathrm{C}$ NMR and XPS spectroscopies provide strong evidence for the formation of $\mathrm{Pt}_{1}(0)$. Based on the extensive DFT structure screening and by comparing the calculated and experimental ${ }^{195} \mathrm{Pt}$ NMR chemical shifts, a pseudo octahedral $\mathrm{Pt}_{1}(0)$ structure, $\left(\mathrm{R}^{1} \mathrm{OR}^{2}\right)_{2} \mathrm{Pt}(0)$ $\mathrm{Cl}_{2}{ }_{2} \mathrm{H}^{+}{ }_{2}$ with weakly coordinated $\mathrm{Pt}_{1}(0)$ is proposed. $\mathrm{Pt}_{1} @ P D M S-P E G$ shows high thermal stability in solution and on support in a moderate temperature range. As a catalyst, it exhibits ultrahigh activity and durability for hydrosilylation with superb selectivity to terminal adduct. The electrondeficient $\mathrm{Pt}_{1}{ }^{\delta+}$ center together with weak oxygen coordination may contribute to the high performance in hydrosilylation. $\mathrm{Pt}_{1} @$ PDMS-PEG could be a potential new generation of hydrosilylation catalyst.

\section{Methods}

Chemicals. 1-Octene (98\%), silica, and PEG-200 were purchased from Aladdin Industrial Corporation. PDMS-2000 were purchased from Alfa Aesar (China) Chemicals Co., Ltd. N, N-dimethylaniline (99\%) and 1,1,1,3,5,5,5-heptamethyltrisiloxane (98\%) were purchased from Tokyo Chemical Industrial Co., LTD. Hydrochloric acid, chloroplatinic acid, ethanol, and ammonium hydroxide were purchased from Sinopharm Chemical Reagent Co., Ltd. PDMS-PEG was purchased from Guangzhou Tinci Materials Technology Co., Ltd. The molecular weight of each block is 30,000 for PDMS and 545 for PEG-12. Ultrapure water purified by Milli-Q Advantage A10 was used.

Sample preparation. Preparation of $\mathrm{Pt}_{1} @ \mathrm{PDMS}-\mathrm{PEG}$ stock solution by reduction of $\mathrm{H}_{2} \mathrm{PtCl}_{6}$ with ethanol: PDMS-PEG $(0.6465 \mathrm{~g})$, ethanol $(135 \mathrm{ml})$, and ultrapure water $(10.2 \mathrm{ml})$ were stirred in a round-bottom flask at $450 \mathrm{rpm}$ at room temperature (RT). After $10 \mathrm{~min}, 4.8 \mathrm{ml} \mathrm{H}_{2} \mathrm{PtCl}_{6}$ solution $\left(1.84 \times 10^{-2} \mathrm{moll}^{-1}\right)$ was added, and the mixture was stirred for 10 more minutes. The solution was refluxed at $105^{\circ} \mathrm{C}$ for $3 \mathrm{~h}$ and then cooled to RT. (For NMR characterization, ethanol and water were evaporated at $40^{\circ} \mathrm{C}$ under reduced pressure).

${ }^{13} \mathrm{CO}$ treatment of $\mathrm{Pt}_{1} @ \mathrm{PDMS}-\mathrm{PEG}$ : Ethanol and water were removed under vacuum from the $\mathrm{Pt}_{1} @ \mathrm{PDMS}-\mathrm{PEG}$ stock solution at $40^{\circ} \mathrm{C}$. The $\mathrm{Pt}_{1} @ \mathrm{PDMS}-\mathrm{PEG}$ sample was purged with $\mathrm{He}$ for $30 \mathrm{~min}\left(100 \mathrm{ml} \mathrm{min}^{-1}\right)$, followed by admission of $5 \%{ }^{13} \mathrm{CO} / \mathrm{He}\left(15 \mathrm{ml} \mathrm{min}^{-1}\right)$ for another $30 \mathrm{~min}$. The sample was flushed with $\mathrm{He}$ for $1 \mathrm{~h}$ to remove free ${ }^{13} \mathrm{CO}$ and collected in a glovebox under $\mathrm{N}_{2}$.

CO treatment of $\mathrm{Pt}_{1} @ P D M S-P E G$ for Far-IR (FIR) characterization: Ethanol and water were removed under vacuum from the $\mathrm{Pt}_{1} @ P D M S-P E G$ stock solution at $40^{\circ} \mathrm{C}$. The $\mathrm{Pt}_{1} @ \mathrm{PDMS}-\mathrm{PEG}$ sample was purged with $\mathrm{He}$ for $30 \mathrm{~min}$ $\left(100 \mathrm{ml} \mathrm{min}^{-1}\right)$, followed by admission of $5 \% \mathrm{CO} / \mathrm{He}\left(15 \mathrm{ml} \mathrm{min}^{-1}\right)$ for another $30 \mathrm{~min}$. The sample was flushed with $\mathrm{He}$ for $1 \mathrm{~h}$ to remove free $\mathrm{CO}$ and collected in a glovebox under $\mathrm{N}_{2}$ before the FIR characterization.

Preparation of $\mathrm{Pt}_{1} @ P D M S-P E G / \mathrm{SiO}_{2}$ : A calculated amount of silica based on the desired final Pt loading was added to $150 \mathrm{ml} \mathrm{Pt} \mathrm{t}_{1} @ \mathrm{PDMS}-\mathrm{PEG}$ stock solution and stirred for $1 \mathrm{~h}$. Ethanol and water were removed at $40^{\circ} \mathrm{C}$ under vacuum. The sample was further vacuum dried for $12 \mathrm{~h}$ at $40^{\circ} \mathrm{C}$. For DRIFT experiment and 
catalytic reactions, the $\mathrm{pH}$ value of the $\mathrm{Pt}_{1} @$ PDMS-PEG stock solution was adjusted to 3.2 by $\mathrm{NH}_{3} \cdot \mathrm{H}_{2} \mathrm{O}$ solution before the evacuation.

${ }^{13} \mathrm{CO}$ treatment of $\mathrm{Pt}_{1} @ \mathrm{PDMS}-\mathrm{PEG} / \mathrm{SiO}_{2}$ : In a quartz tube $200 \mathrm{mg} \mathrm{Pt}_{1} @ \mathrm{PDMS}-$ $\mathrm{PEG} / \mathrm{SiO}_{2}$ was purged with $\mathrm{He}$ for $30 \mathrm{~min}\left(100 \mathrm{ml} \mathrm{min}^{-1}\right)$ and $5 \%{ }^{13} \mathrm{CO} / \mathrm{He}(15 \mathrm{ml}$ $\min ^{-1}$ ) for another $30 \mathrm{~min}$. The sample was flushed with He for $1 \mathrm{~h}$ to remove free gas phase ${ }^{13} \mathrm{CO}$ and collected in a glovebox under $\mathrm{N}_{2}$.

1-Octene disposed $\mathrm{Pt}_{1} @$ PDMS-PEG: Concentrated $150 \mathrm{ml} \mathrm{Pt} \mathrm{t}_{1} @ \mathrm{PDMS}-\mathrm{PEG}$ solution to $20 \mathrm{ml}$. Added $0.0990 \mathrm{~g}$ 1-octene (ten times equivalent to $\mathrm{Pt}_{1}$ ) and $6 \mathrm{ml}$ $\mathrm{CHCl}_{3}$ into the $20 \mathrm{ml}$ concentrated solution (the use of $\mathrm{CHCl}_{3}$ is to enhance the 1-octene dissolution in the system). Stirred for $24 \mathrm{~h}$ at $40{ }^{\circ} \mathrm{C}$ and followed by further concentrating the solution to about $3 \mathrm{ml}$. The sample was collected in a glovebox under $\mathrm{N}_{2}$ prior to the ${ }^{195} \mathrm{Pt}$ NMR measurement.

Ultraviolet (UV)-visible (Vis). UV-Vis spectra was collected on a Shimadzu UV2600 spectrophotometer.

X-ray photoelectron spectra (XPS). The surface composition and the binding energy (B.E.) of the catalyst were determined by XPS on an ESCALAB250 X-ray photoelectron spectrometer with contaminated $\mathrm{C}$ as the internal standard $(\mathrm{C} 1 \mathrm{~s}=$ $284.6 \mathrm{eV})$.

NMR spectroscopy. All solid-state NMR measurements were carried out on a 11.7 T wide-bore Bruker Avance III solid-state NMR spectrometer, operating at a Larmor frequency of $500.13 \mathrm{MHz}$ for ${ }^{1} \mathrm{H}, 125.77 \mathrm{MHz}$ for ${ }^{13} \mathrm{C}$, and $107.21 \mathrm{MHz}$ for ${ }^{195} \mathrm{Pt}$. A $4.0 \mathrm{~mm}$ Bruker multinuclear HX double resonance magic angle spinning (MAS) probe was used. The experiments were acquired at $25^{\circ} \mathrm{C}$ and an MAS frequency of $10 \mathrm{kHz}$, controlled to within $+/-3 \mathrm{~Hz}$ using the Bruker MAS controller. The typical $90^{\circ}$ pulse length was $2.5 \mu \mathrm{s}\left({ }^{1} \mathrm{H}\right), 3.6 \mu \mathrm{s}\left({ }^{13} \mathrm{C}\right)$, and $4.2 \mu \mathrm{s}\left({ }^{(195} \mathrm{Pt}\right)$. Seventy-six thousand two-hundred scans were collected for ${ }^{195} \mathrm{Pt}$ MAS NMR spectra with a recycle delay of $1 \mathrm{~s}$ and $30^{\circ}$ pulse excitation (1.4 us). Eight-thousand one-hundred ninety-two scans were collected for ${ }^{13} \mathrm{C}$ MAS NMR spectra with a recycle delay of $3 \mathrm{~s}$, where ${ }^{1} \mathrm{H}$ SPINAL-64 heteronuclear decoupling with field strength of $90 \mathrm{kHz}$ was applied during the acquisition period. Solution NMR spectra were obtained on Bruker Avance III $600 \mathrm{MHz}$ and $400 \mathrm{MHz}$ using the $5 \mathrm{~mm}$ multinuclear probe. Single pulse and proton decoupling were used for ${ }^{195} \mathrm{Pt}$ and ${ }^{13} \mathrm{C}$ measurements with 3 -s relaxation delay, respectively. The solution and solid-state ${ }^{195} \mathrm{Pt}$ NMR spectra were referenced to a platinum peak of a $1.2 \mathrm{M}$ $\mathrm{Na}_{2} \mathrm{PtCl}_{6} \mathrm{D}_{2} \mathrm{O}$ solution. The chemical shifts of ${ }^{1} \mathrm{H}$ and ${ }^{29} \mathrm{Si}$ NMR spectra were referenced externally to TMS.

Fourier-transform infrared spectroscopy (FTIR). A DiffusIR diffuse reflectance accessory (Pike Technologies) was used for the FTIR measurements. A leveled attenuated total reflectance (ATR) accessory (Pike Technologies) with a $3 \mathrm{~mm}$ diameter diamond plate was used for Middle IR (MIR) and FIR measurements. The FIR instrument (Thermo Scientific Nicolet iS50) is equipped with mercury cadmium telluride (MCT) detector and DTGS/polyethylene detector. The DRIFT measurement has a resolution of $4 \mathrm{~cm}^{-1}$ and 64 scans were collected, while for FIR measurements, 128 scans were collected with a resolution of $16 \mathrm{~cm}^{-1}$. For the DRIFT measurements, the sample was evacuated at $25^{\circ} \mathrm{C}$ for $1 \mathrm{~h}$ before absorption of high purity probing $\mathrm{CO}$ gas. For the FIR measurements, a steady flow of nitrogen was maintained and a high-temperature vacuum-grease-sealed glass lid was used above the sample to prevent air and moisture. Before the FIR experiment, ethanol and water in all the samples were removed by evacuation.

Transmission electron microscopy (TEM) and scanning transmission electron microscope (STEM). STEM analyses were performed with a JEOL JEM-2100F microscope operated at $200 \mathrm{kV}$. TEM analyses were performed with a JEOL JEM$2000 \mathrm{EX}$ microscope operated at $120 \mathrm{kV}$. A few droplets of the stock solution were put on a microgrid carbon polymer supported on a copper grid and allowed to dry out at room temperature for TEM and STEM observations. The samples were evacuated under ultrahigh vacuum for $20 \mathrm{~min}$ in the microscope before observations. For TEM characterization, phosphotungstic acid was used as the staining reagent.

Chloride ion analysis by ion-chromatography. A THERMOICS-5000 ion-chromatography with the Electrochemical Detector (ED) and the AS-11 and AS-22 columns ware used for the detection of $\mathrm{Cl}^{-}$in $\mathrm{Pt}_{1} @ P D M S-P E G$. Before detection, a $5 \mathrm{ml}$ of $\mathrm{Pt}_{1} @ \mathrm{PDMS}$-PEG was diluted to $10 \mathrm{ml}$ with water to reach an appropriate concentration for ion chromatographic analysis.

Computation of NMR shifts. The Amsterdam Density Functional (ADF) approach ${ }^{45}$, by which the relativistic effects for calculating of chemical shielding of heavy atom such as platinum can be implemented, was used. The relativistic effects were treated in the $\mathrm{ADF}$ as all-electron zeroth-order regular approximation (ZORA). For the chemical shielding, the spin-orbital (SO) two-component was used while for the geometry optimization the scalar approximation neglecting SO coupling was utilized. More specifically, as suggested by Autschbach et al. ${ }^{27-29}$, the revised Perdew-Burke-Ernzerhof (revPEB) functional was used for all calculations and the Slate-type of basis sets (TP2Z) were used for ligand atoms and the quadruple-quadruply polarized (QZ4P) ZORA basis was set for Pt, respectively. The calculated chemical shift of the optimized structures was referenced to the calculated isotropic shielding constant $\left(\sigma^{\mathrm{ref}}=2005 \mathrm{ppm}\right)$ of the reference compound $\left[\mathrm{PtCl}_{6}\right]^{2-}$ by the definition of $\delta=\left(\sigma^{\mathrm{ref}}-\sigma\right) /\left(1-\sigma^{\mathrm{ref}}\right) \approx\left(\sigma^{\mathrm{ref}}-\sigma\right)$ with an assumption that $\left(1-\sigma^{\text {ref }}\right) \approx 1$. The geometry of $\left[\mathrm{PtCl}_{6}\right]^{2}$ was optimized $\left(d_{\mathrm{Pt}-\mathrm{Cl}}=2.392 \AA\right)$ using the same method described above prior to the calculation of the shielding constant $\left(\sigma^{\text {ref }}\right)$. Similar ADF method with scalar approximation neglecting SO coupling was used to calcuate ${ }^{13} \mathrm{C}$ chemcial shielding of gas phase $\mathrm{CO}$ and $\mathrm{Pt}$-coordinated $\mathrm{CO}$ in various structures.

General procedure for hydrosilylation. We followed Iwamoto's procedure ${ }^{38}$ to evaluate the $\mathrm{Pt}_{1} @$ PDMS-PEG as the catalyst for the hydrosilylation reaction of 1-octene with 1,1,1,3,5,5,5-heptamethyltrisiloxane (Supplementary Table 7). In all, $0.034 \mathrm{ml} \mathrm{Pt}_{1} @$ PDMS-PEG stock solution (Pt concentration of $5.88 \times 10^{-4} \mathrm{~mol}^{-1}$ ) was added into the reactor. Ethanol and water were evacuated at RT. All reactions were carried out in glovebox. 1-Octene $(4 \mathrm{mmol})$ was added and mixed with the $\mathrm{Pt}_{1} @$ PDMS-PEG [corresponding to $n$ (1-octene): $n\left(\mathrm{Pt}_{1}\right)=200,000: 1$ ] for $3 \mathrm{~min}$ at $25^{\circ} \mathrm{C}$ before reaction. $1,1,1,3,5,5,5$-heptamethyltrisiloxane $(4.4 \mathrm{mmol})$ was then added, and the reaction was carried out at $50^{\circ} \mathrm{C}$. After reaction, $2 \mathrm{mmol} \mathrm{N}$, $\mathrm{N}$-dimethylaniline $(0.2424 \mathrm{~g})$ was added as an internal standard. Products and reactants were characterized by ${ }^{1} \mathrm{H} \mathrm{NMR}\left(400 \mathrm{MHz}, \mathrm{CDCl}_{3}\right.$, and Supplementary Fig. 6). Blank test was run as follows: hydrosilylation reaction was carried out with PDMS-PEG/ethanol-water as the catalyst (without Pt) following the same procedure as for the hydrosilylation of 1-octene catalyzed by Pt $\mathrm{t}_{1} @ \mathrm{PDMS}-\mathrm{PEG}$, No conversion of 1-octene was observed (Supplementary Table 7).

The reported conversion measurement was repeated at least three times under the same condition, and the uncertainty was typically below $5 \%$. The average value of multiple measurements is presented in the paper.

The turnover frequency (TOF), defined as the number of moles of terminal product $(\mathbf{T})$ yield per mole of $\mathrm{Pt}_{1}(0)$ within a unit time, is calculated in unit of $\mathrm{h}^{-1}$ according to

$$
\begin{aligned}
\mathrm{TOF} & =\frac{n_{\mathrm{T}}}{n_{\mathrm{P}}} \times \frac{1}{t} \\
& =\frac{n_{\text {olefin. } 0} \times \text { yield }_{\mathrm{T}}}{n_{\mathrm{Pt}}} \times \frac{1}{t}
\end{aligned}
$$

Since the conversion reached nearly completion in a minute, the initial TOF was calculated by taking $t$ as $1 \mathrm{~min}$ for the catalytic reaction under consideration.

$n_{\text {olefin, } 0}$ is the initial number of moles of 1-octene used in the reaction. Note

that $n_{1-\text { octene, } 0}$ is $4 \mathrm{mmol}$.

$n_{\mathrm{T}}$ is the number of moles of product, $\mathrm{T}$ (terminal adduct).

$n_{\mathrm{Pt}}$ is the number of moles of $\mathrm{Pt}$ added in the reaction.

$t$ is the reaction time. The conversion value was calculated at $t=1 \mathrm{~min}$

$$
\text { yield }_{\mathrm{T}}=\text { conversion } \times \text { selectivity }
$$

Turnover numbers (TONs). TON of $\mathrm{Pt}_{1} @ \mathrm{PDMS}-\mathrm{PEG}$ in the hydrosilylation reaction between 1-octene and 1,1,1,3,5,5,5-heptamethyltrisiloxane: $0.0068 \mathrm{ml}$ $\mathrm{Pt}_{1} @$ PDMS-PEG stock solution (diluted 10 times, $5.88 \times 10^{-5} \mathrm{~mol} \mathrm{l}^{-1}, 4 \times 10^{-10}$ $\mathrm{mol}$ ) was added into the round-bottom flask, followed by evacuation of ethanolwater. All reaction was carried out in glovebox. 1-Octene $(40 \mathrm{mmol})$ was added and mixed with the $\mathrm{Pt}_{1} @$ PDMS-PEG [ $n$ (1-octene): $\left.n\left(\mathrm{Pt}_{1}\right)=1 \times 10^{8}: 1\right]$ for $3 \mathrm{~min}$ at $25^{\circ} \mathrm{C}$ before reaction. $1,1,1,3,5,5,5$-heptamethyltrisiloxane $(48 \mathrm{mmol})$ was then added, and the mixture was refluxed at $70^{\circ} \mathrm{C}$. After the completion of the reaction (verified by ${ }^{1} \mathrm{H}$ NMR), add more 1-octene and 1,1,1,3,5,5,5-heptamethyltrisiloxane $(1: 1.2)$ into the reactor and continue the reaction.

Catalyst recycle. After the hydrosilylation reaction between 1-octene and $\left(\mathrm{Me}_{3} \mathrm{SiO}\right)_{2} \mathrm{MeSiH}$ (1-octene: $0.4488 \mathrm{~g},\left(\mathrm{Me}_{3} \mathrm{SiO}\right)_{2} \mathrm{MeSiH}: 0.89 \mathrm{~g}$ ) finished, the solution was centrifuged. In all, $0.6694 \mathrm{~g}$ reaction mixture was taken out from the upper solution, and analyzed by ${ }^{1} \mathrm{H}$ NMR. The remaining solution $(0.6694 \mathrm{~g})$ was used for the subsequent hydrosilylation reaction. For the reuse test, $0.4488 \mathrm{~g}$ 1 -octene and $0.89 \mathrm{~g}\left(\mathrm{Me}_{3} \mathrm{SiO}\right)_{2} \mathrm{MeSiH}$ was added. After reaction, solution was centrifuged. In all, $1.3388 \mathrm{~g}$ (equal to the amount of added reactants) reaction mixture was taken out from the upper solution, and analyzed by ${ }^{1} \mathrm{H} N M R$, while the remaining solution $(0.6694 \mathrm{~g})$ was used for the subsequent hydrosilylation reaction. For the following reuses, the added amounts of 1-octene and $\left(\mathrm{Me}_{3} \mathrm{SiO}\right)_{2} \mathrm{MeSiH}$ were always 0.4488 and $0.89 \mathrm{~g}$, respectively. After each reaction, the amount of reaction mixture taken out for ${ }^{1} \mathrm{H}$ NMR from the upper solution after centrifugation was always $1.3388 \mathrm{~g}$ (equal to the amount of added reactants), and the remaining solution was kept at $0.6694 \mathrm{~g}$ for the subsequent hydrosilylation reaction.

\section{Data availability}

The data that support the findings in this study are in the published article and/or its Supplementary Information files. The whole datasets are available from the 
corresponding author on reasonable request. The source data are provided as a Source Data file.

Received: 16 August 2018 Accepted: 29 January 2019

Published online: 01 March 2019

\section{References}

1. Wang, A., Li, J. \& Zhang, T. Heterogeneous single-atom catalysis. Nat. Rev Chem. 2, 65-81 (2018).

2. Yang, X. -F. et al. Single-atom catalysts: A new frontier in heterogeneous catalysis. Acc. Chem. Res. 46, 1740-1748 (2013).

3. Flytzani-Stephanopoulos, M. Gold atoms stabilized on various supports catalyze the water-gas shift reaction. Acc. Chem. Res. 47, 783-792 (2014).

4. Qiao, B. et al. Single-atom catalysis of CO oxidation using Pt1/FeOx. Nat. Chem. 3, 634-641 (2011).

5. Wei, S. et al. Direct observation of noble metal nanoparticles transforming to thermally stable single atoms. Nat. Nanotechnol. 13, 856-861 (2018).

6. Liu, W. et al. Discriminating catalytically active FeNx species of atomically dispersed Fe-N-C catalyst for selective oxidation of the C-H bond. J. Am. Chem. Soc. 139, 10790-10798 (2017).

7. Wei, H. et al. FeOx-supported platinum single-atom and pseudo-single-atom catalysts for chemoselective hydrogenation of functionalized nitroarenes. Nat. Commun. 5, 5634 (2014).

8. Liu, W. et al. Single-atom dispersed $\mathrm{Co}-\mathrm{N}-\mathrm{C}$ catalyst: structure identification and performance for hydrogenative coupling of nitroarenes. Chem. Sci. 7, 5758-5764 (2016).

9. Chen, S. et al. Initial reaction mechanism of platinum nanoparticle in methanol-water system and the anomalous catalytic effect of water. Nano Lett. 15, 5961-5968 (2015).

10. Appleton, T. G., Clark, H. C. \& Manzer, L. E. The trans-influence: Its measurement and significance. Coord. Chem. Rev. 10, 335-422 (1973).

11. Stubenrauch, C., Wielputz, T., Sottmann, T., Roychowdhury, C. \& DiSalvo, F. J. Microemulsions as templates for the synthesis of metallic nanoparticles. Colloids Surf. A 317, 328-338 (2008).

12. Jana, N. R., Gearheart, L. \& Murphy, C. J. Seed-mediated growth approach for shape-controlled synthesis of spheroidal and rod-like gold nanoparticles using a surfactant template. Adv. Mater. 13, 1389-1393 (2001).

13. Parera, E., Comelles, F., Barnadas, R. \& Suades, J. New surfactant phosphine ligands and platinum(II) metallosurfactants. Influence of metal coordination on the critical micelle concentration and aggregation properties. Langmuir: ACS J. Surf. Colloids 26, 743-751 (2010).

14. de la Iglesia, P., Jaeger, V. W., Xi, Y., Pfaendtner, J. \& Pozzo, L. D. Structure characterization and properties of metal-surfactant complexes dispersed in organic solvents. Langmuir: ACS J. Surf. Colloids 31, 9006-9016 (2015).

15. Kickelbick, G., Bauer, J., Huesing, N., Andersson, M. \& Holmberg, K. Aggregation behavior of short-chain PDMS-b-PEO diblock copolymers in aqueous solutions. Langmuir: ACS J. Surf. Colloids 19, 10073-10076 (2003).

16. Schreyeck, G. \& Marie, P. Kinetics of the adsorption of a PDMS-g-PEO copolymer at the PDMS/PEO interface. Langmuir 15, 8212-8219 (1999).

17. Wang, S. -R. \& Tseng, W. J. Aggregate structure and crystallite size of platinum nanoparticles synthesized by ethanol reduction. J. Nanopart. Res. 11, 947-953 (2009).

18. Chen, C. -W. \& Akashi, M. Synthesis, characterization, and catalytic properties of colloidal platinum nanoparticles protected by poly $(\mathrm{N}$ isopropylacrylamide). Langmuir 13, 6465-6472 (1997).

19. $\mathrm{Li}, \mathrm{H}$. et al. Isomerization characteristics and the coordination chemistry of metal chlorides in 1-butyl-3-methylimidazolium chloride. ACS Catal. 4 , 4446-4454 (2014).

20. Li, H. \& Zhang, Z. C. Far reaching potentials of far infrared spectroscopy in catalysis research. Chin. J. Catal. 37, 637-643 (2016).

21. Teranishi, T., Hosoe, M., Tanaka, T. \& Miyake, M. Size control of monodispersed Pt nanoparticles and their 2D organization by electrophoretic deposition. J. Phys. Chem. B 103, 3818-3827 (1999).

22. Shelimov, B., Lambert, J. F., Che, M. \& Didillon, B. Application of NMR to interfacial coordination chemistry: A Pt-195 NMR study of the interaction of hexachloroplatinic acid aqueous solutions with alumina. J. Am. Chem. Soc. 121, 545-556 (1999).

23. Harris, R. K., McNaught, I. J., Reams, P. \& Packer, K. J. Multinuclear highresolution solid-state magnetic-resonance studies of some platinum(Ii) complexes with phosphorus-containing ligands. Magn. Reson. Chem. 29, 60-72 (1991)

24. Pellechia, P. J., Gao, J., Gu, Y., Ploehn, H. J. \& Murphy, C. J. Platinum ion uptake by dendrimers: An NMR and AFM study. Inorg. Chem. 43, 1421-1428 (2004).
25. Albinati, A., Isaia, F., Kaufmann, W., Sorato, C. \& Venanzi, L. M. Solution studies of complexes of the types trans $-\mathrm{PtCl} 2 \mathrm{~L}(1,4$-diazine $)$ and trans $-\mathrm{LCl} 2 \mathrm{Pt}$ ( $\mu$-1,4-diazine)PtCl2L ( $\mathrm{L}=$ Phosphine, C2H4). X-ray Structures of Pt2Cl4L2 (ppz) $(\mathrm{L}=\mathrm{C} 2 \mathrm{H} 4, \mathrm{PEt} 3 ; \mathrm{ppz}=2,5$-Dimethylpyrazine $)$ and the relative trans influence of alkene and tertiary phosphine ligands. Inorg. Chem. 28, 1112-1122 (1989)

26. Kalodimos, C. G., Gerothanassis, I. P., Pierattelli, R. \& Ancian, B. Carbon-13 and oxygen-17 chemical shifts-16O-18O isotope effects on $13 \mathrm{C}$ chemical. Inorg. Chem. 38, 4283-4293 (1999).

27. Sutter, K. \& Autschbach, J. Computational study and molecular orbital analysis of NMR shielding, spin-spin coupling, and electric field gradients of azido platinum complexes. J. Am. Chem. Soc. 134, 13374-13385 (2012).

28. Autschbach, J. \& Le Guennic, B. Solvent effects on 195Pt and 205Tl NMR chemical shifts of the complexes $[(\mathrm{NC}) 5 \mathrm{Pt}-\mathrm{Tl}(\mathrm{CN}) \mathrm{n}] \mathrm{n}-(\mathrm{n}=0-3)$, and $[(\mathrm{NC})$ $5 \mathrm{Pt}-\mathrm{Tl}-\mathrm{Pt}(\mathrm{CN}) 5] 3$ - studied by relativistic density functional theory. Chemistry 10, 2581-2589 (2004).

29. Sterzel, M. \& Autschbach, J. Toward an accurate determination of $195 \mathrm{Pt}$ chemical shifts by density. Inorg. Chem. 45, 3316-3324 (2006).

30. Mondloch, J. E., Özkar, S. \& Finke, R. G. "Weakly ligated, labile ligand" nanoparticles: The case of $\operatorname{Ir}(0) \mathrm{n} \cdot(\mathrm{H}+\mathrm{Cl}-) \mathrm{m}$. ACS Omega 3, 14538-14550 (2018).

31. Romeo, M., Majerus, J., Legare, P., Castellani, N. J. \& Leroy, D. B. Photoemission-study of Pt Adlayers on Ni(111). Surf. Sci. 238, 163-168 (1990)

32. Bancroft, G. M. et al. ESCA study of sputtered platinum films. Anal. Chem. 47, 586-588 (1975).

33. Bagnoli, F. et al. Halo-carbonyl complexes of platinum(II) and palladium(II). J. Organomet. Chem. 622, 180-189 (2001).

34. Discher, D. E. \& Eisenberg, A. Polymer vesicles. Science 297, 967-973 (2002).

35. Ding, K. et al. Identification of active sites in CO oxidation and water-gas shift over supported Pt catalysts. Science 350, 189-192 (2015).

36. Denmark, ScottE. \& Wang, Z. Cross-coupling of vinylpolysiloxanes with aryl iodides. J. Organomet. Chem. 624, 372-375 (2001).

37. Marko, I. E. et al. Selective and efficient platinum(0)-carbene complexes as hydrosilylation catalysts. Science 298, 204-206 (2002).

38. Troadec, T. et al. Silacyclopropylideneplatinum $(0)$ complex as a robust and efficient hydrosilylation catalyst. Inorg. Chem. 55, 8234-8240 (2016).

39. Buisine, O. et al. Second generation N-heterocyclic carbene- $\mathrm{Pt}(0)$ complexes as efficient catalysts for the hydrosilylation of alkenes. Chem. Commun. $\mathbf{0}$, 3856-3858 (2005).

40. Iimura, T., Akasaka, N., Kosai, T. \& Iwamoto, T. A Pt(0) complex with cyclic (alkyl)(amino)silylene and 1,3-divinyl-1,1,3,3-tetramethyldisiloxane ligands: synthesis, molecular structure, and catalytic hydrosilylation activity. Dalton Trans. 46, 8868-8874 (2017).

41. Chen, Y. et al. Discovering partially charged single-atom Pt for enhanced anti-Markovnikov alkene hydrosilylation. J. Am. Chem. Soc. 140, 7407-7410 (2018).

42. Meister, T. K. et al. Platinum catalysis revisited-unraveling principles of catalytic olefin hydrosilylation. ACS Catal. 6, 1274-1284 (2016).

43. Markó, I. E. et al. Highly active and selective platinum $(0)$-carbene complexes. Efficient, catalytic hydrosilylation of functionalised olefins. Adv. Synth. Catal. 346, 1429-1434 (2004).

44. Stein, J., Lewis, L. N., Gao, Y. \& Scott, R. A. In Situ determination of the active catalyst in hydrosilylation reactions using highly reactive $\mathrm{Pt}(0)$ catalyst precursors. J. Am. Chem. Soc. 121, 3693-3703 (1999).

45. Baerends, E. J. et al. Basic Aspects of Density Functional Theory. in Computational Methods in Catalysis and Materials Science: An Introduction for Scientists and Engineers. eds van Santen, R. \& Sautet, P. (Wiley, New Jersey, 2009).

\section{Acknowledgements}

This work was supported by the "Global Expert" program funding of China and by the State Key Laboratory of Catalysis, Dalian Institute of Chemical Physics, Chinese Academy of Sciences. Professors Ulrich Mueller-Westerhoff of University of Connecticut, Mayfair Kung and Harold Kung of Northwestern University offered helpful suggestions in the revision of the manuscript. S.B. and Z.C. thank Professors Cecil Dybowski and Andrew Teplyakov (University of Delaware) for the helpful discussion on the characterization of subnano platinum particles using ${ }^{195} \mathrm{Pt}$ NMR spectroscopy and the DFT calculations of the model structures. The ${ }^{195} \mathrm{Pt}$ and ${ }^{13} \mathrm{C}$ NMR measurements at University of Delaware were made possible by the Delaware COBRE program, supported by a grant from the National Institute of General Medical Sciences-NIGMS (5 P30 GM110758-02) from the National Institutes of Health

\section{Author contributions}

Z.C.Z. conceived, designed, and led the study. K.L. designed and performed bulk of the experiments in synthesis, characterization and catalytic reactions. J.M. and X.G. 
conducted preliminary synthesis and characterization. S.B. and G.H. carried out NMR measurements and analysis of the NMR results. S.B. and K.L. carried out the DFT calculations on the model structures. Z.X. assisted K.L. in analyzing the NMR results of hydrosilylation reaction. P.Y. assisted K.L. in the IR study and chloride ion analysis by ion-chromatography. H.L. assisted K.L. in the far-IR study.

\section{Additional information}

Supplementary Information accompanies this paper at https://doi.org/10.1038/s41467019-08804-y.

Competing interests: The authors declare no competing interests.

Reprints and permission information is available online at http://npg.nature.com/ reprintsandpermissions/

Journal peer review information: Nature Communications thanks the anonymous reviewers for their contribution to the peer review of this work. Peer reviewer reports are available.
Publisher's note: Springer Nature remains neutral with regard to jurisdictional claims in published maps and institutional affiliations.

\section{(c) (i)}

Open Access This article is licensed under a Creative Commons Attribution 4.0 International License, which permits use, sharing, adaptation, distribution and reproduction in any medium or format, as long as you give appropriate credit to the original author(s) and the source, provide a link to the Creative Commons license, and indicate if changes were made. The images or other third party material in this article are included in the article's Creative Commons license, unless indicated otherwise in a credit line to the material. If material is not included in the article's Creative Commons license and your intended use is not permitted by statutory regulation or exceeds the permitted use, you will need to obtain permission directly from the copyright holder. To view a copy of this license, visit http://creativecommons.org/ licenses/by/4.0/.

(C) The Author(s) 2019 